\title{
The Impact of Green Buildings on Energy Consumption in Some Middle East Countries (Arabic Union)
}

\author{
Mahmod Tayb M. Yahya \\ Department of Civil Engineering, Sabratha University, Sabratha, Libya \\ Email: Eng_mahmud2003@yahoo.com
}

\begin{abstract}
Green buildings will have a significant impact in helping the Middle East countries of the suffering incurred in resolving the power outage problems as a result of increasing growing energy demand. Green buildings could help the inability of some of Arabic countries to provide increased volume on demand, especially in the summer time, which cost their budget huge expenses. On the other hand, a significant pollution to the environment due to the large reliance on environmentally harmful conventional stations to provide the bulk of the electricity; however keeps the deficit remains which led to several initiatives, including the emergence of a new project, which is a electrical connection between these countries to resolve this crisis, one of the costly projects. This paper has put up a practical solution which renovate government and commercial buildings into green buildings to save energy consumption. Government and commercial buildings consume about $16 \%$ to $50 \%$ of the total electricity consumed in the Arabic countries according to the Arab Union for Electricity ; in other words, this paper has examined the impact of green buildings save energy consumed in the Arabic region, and it has been showed that the amount of electrical power could be saved by using green buildings in each country. Using green buildings technique in the government and commercial buildings leads to release the stresses on the budget of these countries by saving the used money to produce that amount of electricity for these buildings, also this saving has been taking in the consecration in this paper; as well as It was studied the impact of these buildings to reduce environmentally harmful emissions from power plants by reducing the productivity power of these planets. Reducing the productivity power in Arabic countries means reducing greenhouse gas emissions. Implementing the idea of green buildings result the reduction the stress on the budget by reducing the drain the energy sector, solving outage power problems, and reducing environmental pollution.
\end{abstract}

Index Terms - green buildings, energy consumption, energy efficiency, commercial buildings, government buildings, pollution

\section{INTRODUCTION}

While energy sources constitute a pressing concern for the countries of the world due to the importance of energy in the global economy. Issued the "International

Manuscript received July 23, 2017; revised November 1, 2017.
Atomic Energy Agency," a publication says that the existing buildings are responsible for more than $40 \%$ of total primary energy consumption in the world, and about $24 \%$ of global emissions of carbon dioxide [1]. It is worth mentioning that the Arab countries are still in a phase of economic growth in various fields, which leads to increased energy demand, therefore, the electric power in the Arab countries continues to grow annually.

The energy sector in the Arab region is one of the most promising investment sectors due to the continuous increase in electricity consumption in conjunction with the high annual increase in population. The growth of large cities has many requirements, high standard of living, high increased use of air conditioners, and electrical appliances. The any disruption in oil production and transport operations, or the occurrence of any territorial disputes, effect leads to cut the road from the oil-producing country, aggravate matters in consumer countries with high bills on the budget of these countries. And that the price was liberated in the scope of competition and exploitation of political and economic conditions and the effects on the consumer are big also. The countries with little energy production, or those are running out of oil, the increasing demand for it, will be affected largely in the midst of evolving uses stemming from industrial, social and economic progress. All these mentioned reasons make researchers to take action and harsh measures to curb consumption and energy conservation and raise the efficiency of use, and this is what needs to be Arab governments search for investments in power generation.

Green building is one of the latest environmental solutions (sustainable building solutions). The International Energy Agency estimated the size of the primary energy needs of the world by $55 \%$ by the year 2030 with a budget estimated at 33 trillion dollar, which is the size required to meet and implement those needs and based on that adopted many Arab countries general trend would provide many of the facilities necessary to activate the green buildings and sustainable operations. [2].

The modern trend is to build green and sustainable energy conservation priorities and provided as much as possible and work to expand in green construction 
industry worldwide; as well as green buildings aim to protect the environment from pollution [3].

One of the bottom lines of the Green Building Project is to save electrical energy consumption in general, such as the energy used for cooling, lighting, and water heating in particular. In addition to the rationalization of water consumption, reduces carbon dioxide emissions, and improves the quality of indoor and outdoor air environment at buildings, and thus improve the health of society [1]. Green buildings lead to raise productivity and boost the economy in various sectors, also reduce the environmental pollution caused by power plants.

\section{RESEARCH PROBLEM}

The problem is increasing electricity consumption growth in the Arabic regions and having a difficulty to cover this growing demand for energy. Increasing energy consumption leads to increased pollution level of adoption of these countries mainly on nonenvironmentally friendly plants, which increases the level of greenhouse gases in the area. Governments of these countries have to be find quick and inexpensive solutions to solve this problem through renovation of government and commercial buildings to environmentally friendly buildings.

\section{THE IDEA OF THE RESEARCH}

Taking the advantage of green buildings to reduce electricity consumption, as well as reducing the production capacity of the power plants to reduce emissions. This paper has focused on benefiting from the orientation of the building in the natural lighting to reduce the use of electric lights during the daytime. Taking the advantage of the same orientation to minimize the thermal transferred into the building of the sun rays, so as to minimize the use of air conditioners and providing thermal comfort for humans and create a better relationship between them, depending on the longitude and latitude in these countries. Study the flood light and the time of the brightness of the sun, also the rehabilitation of electrical lighting according to the regulations of green buildings. It has been extracting savings rates in the power of Arabic countries by designing a green building and circulated as a case study on all of these countries were, and cover energy remaining after the savings of the energy needed by the building and needed to run it to benefit from the radiation of sun by using solar panels. The study showed that the roofs of environmental and commercial buildings are enough to suit solar panels to cover the remaining amount of electricity. Renovated environmental and commercial buildings would be autonomous of any provision of electricity by $100 \%$. It has been deducted the saving percentage of total energy consumption.

The selection of government and commercial buildings to renovate them to green buildings into three main reasons. First is considered an important area to rationalize the use of electrical energy because they are exposed to great extravagance in energy consumption .Second, spending on government buildings are usually funded from the country budget, and therefore any savings achieved due directly results to country. Third striking similarity in the patterns of the electric power consumption of government and commercial buildings helps generalizability implement power saving opportunities at all government and commercial buildings in these countries.

\section{Why SHOULD FocUS ON GREEN BUILDINGS IN MidDLE EAST COUNTRIES}

The call for the deployment of green building culture and creating environmentally friendly buildings are an invitation to deal with better environment through modern technology, ranging from practical application design for the building, all the way to approach reducing energy consumption by using modern insulators techniques, energy alternatives, and materials with free of harmful chemicals and others [4]. Green buildings should be civilized alternative to traditional buildings, because they take the consideration during design environmental protection against pollution, with the use of recycled materials, and dependence on natural resources such as sunlight, wind and rainwater, all in order to minimize, and reach the lowest limit of the negative impact of buildings on the environment, with keeping in mind the improvement of the quality of living [5]. Arab countries are also considered a fertile environment for green buildings to provide all the natural resources that can be exploited through these buildings to get rid of some bad habits such as lack of rationalization of energy consumption and increase wasteful electricity consumption, as well as increased pollution levels.

\section{POPUlATION GROWTH AND ENERGY CONSUMPTION}

There is a difference in the growth rates of energy consumption from an Arab country to another due to the availability of energy sources from region to region. Statistics indicate that have been obtained from the Arab Union for Electricity in 2013 to increase the average per capita consumption of electricity by about $47 \%$ compared to 2010 , bringing the average per Arab citizen to 5133 $\mathrm{kW}[6]$.

Thus, it notice from the statistics obtained from the Arab Union for Electricity, there is a significant increase for the countries of the Middle East on the demand for electricity making up to the proportion of $6.2 \%$ in the period between 2000 to 2010 to reach $655.8 \mathrm{TWh}$ in 2010 The demand relative larger increased to reach $19.4 \%$ in the period between 2010 to 2014 to reach 1166.4 TWh. The same report predicted that demand up to about 1598 Terra Watt hour in 2019 to 2083.9 TWh in 2024 [2]. It could be noticing from all these statistics that those countries experiencing huge industrial evolution, which leads to the huge demand for energy, which leads to increase the burden on the countries budget, also increase the sources of pollution as a result of the adoption of the bulk of the power plants on contaminated sources. 
Table I shows the growth and demand for energy ratio for the year 2014 according to the latest statistics statistical bulletin issued by the Arab Union for Electricity.

TABLE I. POPULATION AND ENERGY CONSUMPTION FOR ARABIC COUNTRIES REF. [7]

\begin{tabular}{|c|c|c|c|c|}
\hline \multirow{2}{*}{ Country } & \multirow{2}{*}{$\begin{array}{c}\text { Energy } \\
\text { Generated Per } \\
\text { Capital } \\
\text { (Kwh) }\end{array}$} & \multirow{2}{*}{$\begin{array}{c}\text { Population } \\
\text { Supplied } \\
(\%)\end{array}$} & \multicolumn{2}{|c|}{$\begin{array}{c}\text { Population } \\
\left(10^{\wedge} 6\right)\end{array}$} \\
\hline & & & $\begin{array}{c}\text { Growth } \\
(\%)\end{array}$ & 2014 \\
\hline Jordan & 2782 & 99.9 & 2.3 & 6.7 \\
\hline UAE & 11772 & 100 & - & 9.3 \\
\hline Bahrain & 12344 & - & 3.3 & 1.3 \\
\hline Tunisia & 1286 & 99.5 & - & 10.9 \\
\hline Algeria & 1527 & 99 & 1.5 & 39.5 \\
\hline $\begin{array}{c}\text { Saudi } \\
\text { Arabia }\end{array}$ & 10157 & 99 & 2.6 & 30.7 \\
\hline Sudan & 317 & 31 & 3 & 37.3 \\
\hline Syria & 1100 & 99.9 & - & 22 \\
\hline Iraq & 2780 & - & 2.6 & 36 \\
\hline Oman & 6900 & - & 0.2 & 4.2 \\
\hline Palestine & 1196 & 99 & 4 & 4.3 \\
\hline Qatar & 16840 & 100 & - & 2 \\
\hline Kuwait & 15878 & 89 & 3.3 & 4.1 \\
\hline Lebanon & 2500 & 99 & 1.4 & 5 \\
\hline Libya & 2326 & 99 & - & 6.3 \\
\hline Egypt & 1943 & 99.4 & 2.6 & 86.3 \\
\hline Morocco & 1019 & - & 1.1 & 33.3 \\
\hline Yemen & 273 & 52 & 8.6 & 26.5 \\
\hline
\end{tabular}

\section{ELECTRICITY PRODUCTION IN THE ARAB WORLD}

Total composite capacity for electricity production in the Arab world reached approximately 1233672 megawatts in 2013, according to the statistical bulletin of the Arab Union for Electricity [8]. Fig. 1 illustrates that the percentage contribution of each source from different sources to produce energy in the Arabic countries. Increasing use of electrical energy as a reaction to the increasing population growth and expanding infrastructure and industrial areas, which led to an increase rate of $18.7 \%$ from 2010 to 2013 . Electricity produced had reached in 2013 to 967.1 TWh [7]. These percentages are expected to increase significantly in the coming years due to these countries are still in the process of growth, unlike other developed countries. Fig. 2 illustrates the heavy reliance on oil and gas derivatives to meet the production of electricity, for that Arabic countries are costing a huge amount of money; on the other hand, emissions resulting from burnings negatively affect on the environment.

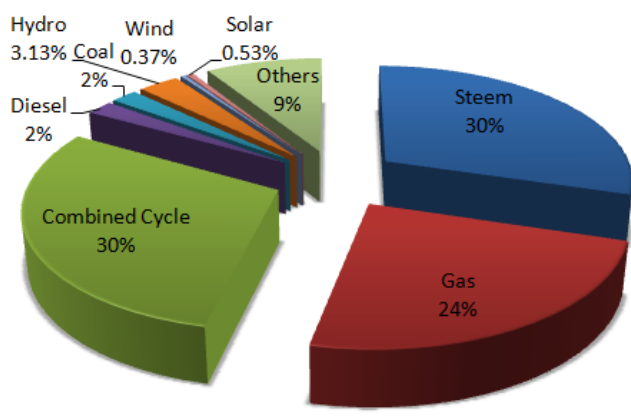

Figure 1. Sources of energy production in the Middle East (Source Statistical Bulletin for 2013 of the Arab Union for Electricity) Ref. [7]

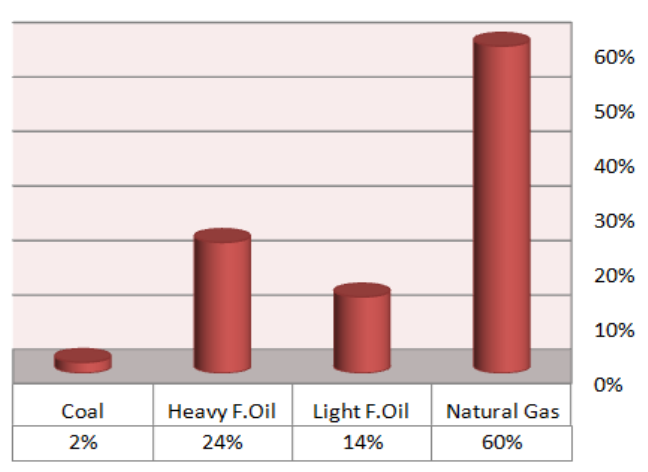

Figure 2. Proportions of fuel consumption in power plants (statistical deployment in 2013 of the Arab Union for Electricity source) Ref. [7]

\section{ELECTRICITY CONSUMPTION IN GOVERNMENT AND COMMERCIAL BUILDINGS}

This paper clarified the proportion of electrical energy consumption for each category by using a case study conducted on the design of green buildings within the government and commercial buildings in detail. It was chosen as a government building to the similarity of government and commercial buildings in the proportions of electricity consumption in order to adopt them as a general case study to conduct the study on the rest of the government and commercial buildings in all Arabic countries. Fig. 3 shows the energy consumption rates for each category.

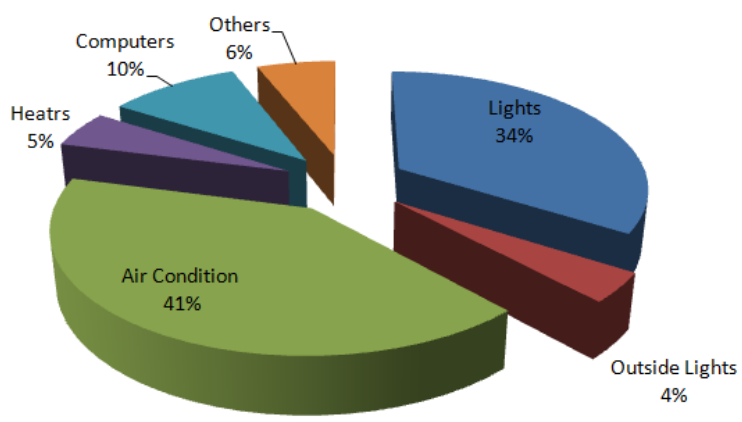

Figure 3. Proportion of electricity consumption for each category within the building. Ref. [9], [10]

\section{EFFICIENCY OF GREEN BUILDINGS}

\section{A. Exploitation of Daylight Saving in Industrial Lighting}

Has been taking into account the brightness of the sun in summer and winter period, and take advantage of reflection factor $\mathrm{R}$ for walls and floors, as well as benefit from the orientation of the building and the windows number and areas and quality of the glass used. It has been balancing between entering natural day light the building and the amount of heat in order to avoid thermal overload, which may result from excessive natural lighting. The average natural day lighting in the summer is $4.98 \%$ which is a very great number, but in the winter it is $1.98 \%$ and this number is considered good compared 
to the desired number which is $2 \%$ [11]. The following equation was adopted for calculating lighting DF.

$$
\mathrm{DF}=\frac{\mathrm{T} * \mathrm{M} * \text { WINDOW AREA } * \text { SKY ANGLE }}{\text { ROOM SURFASE AREA } *(1-\mathrm{R} * \mathrm{R})}+\cdots
$$

$\mathrm{T}=$ diffuse transmittance of glazing,

$\mathrm{M}=$ maintenance factor for glazing, and

$\mathrm{R}=$ average reflectivity of room surfaces

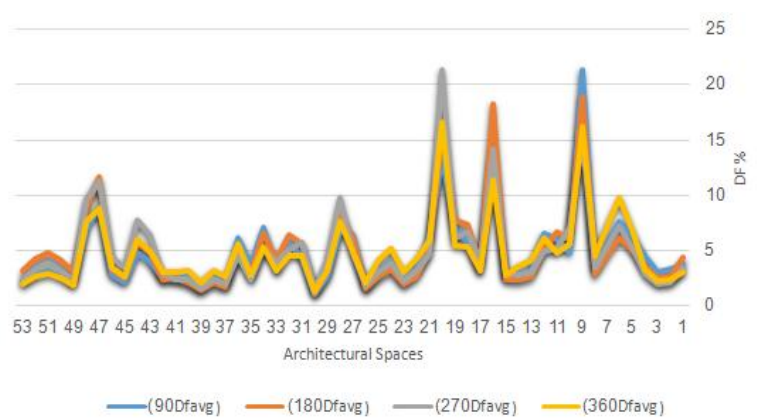

Figure 4. Rate of natural lighting in all directions. Ref. [9]

It is clear from Fig. 4 that the lighting coefficient DF for different directions close to each other which means in any direction can be the building be oriented to take advantage of natural lighting and making that easier for us to avoid thermal overload, which may result from directing the building to get the most amount of lighting. This shows that it could renovate any existing building in any direction in these countries to take the advantage of the day light. Depending on the natural lighting during the day time is reduced electrical lighting. The study was conducted on this subject have proved that it is possible to diminish the amount of energy used for electrical lighting during day light compared with the same building in its traditional condition to about $39.5 \%$, and Fig. 5 illustrates this. That means the electrical power required for lighting these buildings during the day to get good lighting during working time could be reduced to $39.5 \%$.

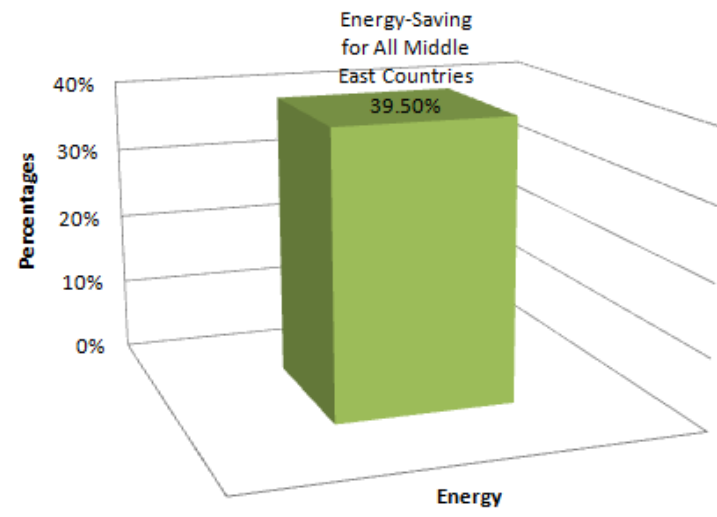

Figure 5. Savings in electricity consumption by taaking the advantage of natural lighting

\section{B. The Use of Recommended Lamps by LEED}

It has been used electrical lamps with high iceberg, low heat emissions, and low electricity consumption in renovated buildings compared to conventional electrical lamps. The price was considered in the selection of these lamps too (There are still more efficient lamps which can be used, but they are costly), so the price was also in the selection of these lamps. The type of lumps which was used in this study is "MASTER TL5 HO 90 Deluxe" [12], [13]. The specifications of this type of lamps are voltage 53 Watts, emanation iceberg 4300 lumen as life 24000 hours, and Color rendering index $(\mathrm{Ra})=92$ any optical output is excellent, which means that the optical output excellent, comfortable and color where [12], [13]. This chosen type of lamp in this study can be used in the halls and laboratories, offices, hospitals and jewelry shops that need to be excellent colors. These lamps are suitable for university environment as well. These kind of lamps are perfect for public buildings such as government and commercial buildings. These lamps were installed in spaces, rooms, halls, and offices in environmental and commercial buildings in this research.

Fig. 6 shows the proportion of savings resulting from the use of the green buildings, and shows great savings in the amount of energy, which reaches $55 \%$ as well as reduction of the thermal use.

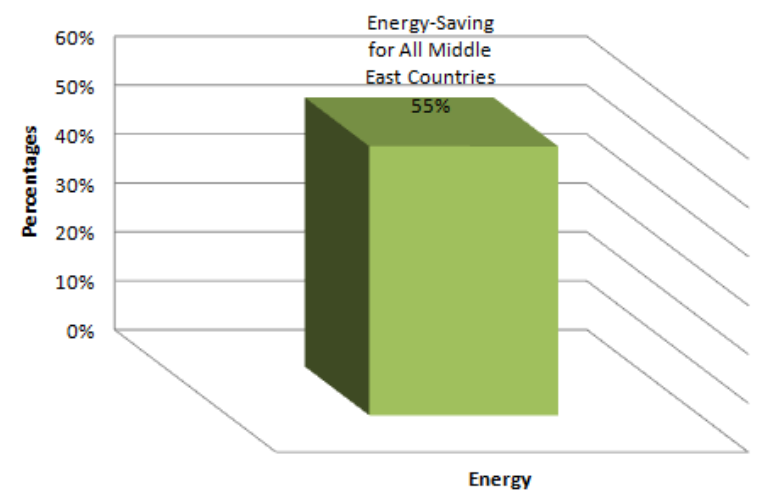

Figure 6. Savings in electricity consumption by using lamps recommended by LEED

\section{The Outer Shell of the Building}

The outer shell is divided into two main sections:

Section 1: The glass which was used in the case study has accepted iceberg light according to LEED, and at the same time the price was considered in the selection. The type of glass was used is "Low emissivity double glazinggreen". Where the thermal transition coefficient is $\mathrm{U}=1.9$, and coefficient of visual permeability is $\mathrm{T}=0.69$ [14], [15]. The color of glass is green, which means no need for shading because the glass is not transparent; in addition to that this type is commonly used in the modern constructions, because it is suitable in terms of price and in terms of performance.

Section 2: It was addressed to the issue of the appropriate direction to orient the building where taking the advantages and disadvantages of each direction, and then make the necessary calculations have been identified the best and worst the direction of the building. The exposed are to the sun radiation was isolated with insulation to reduce thermal translation into the building; as well as overhang were put on the Windows to block out sun rays. 
Fig. 7 shows the percentage of energy savings from section 1 and 2 in the green building compared to traditional building and went savings ratio to about $39 \%$.

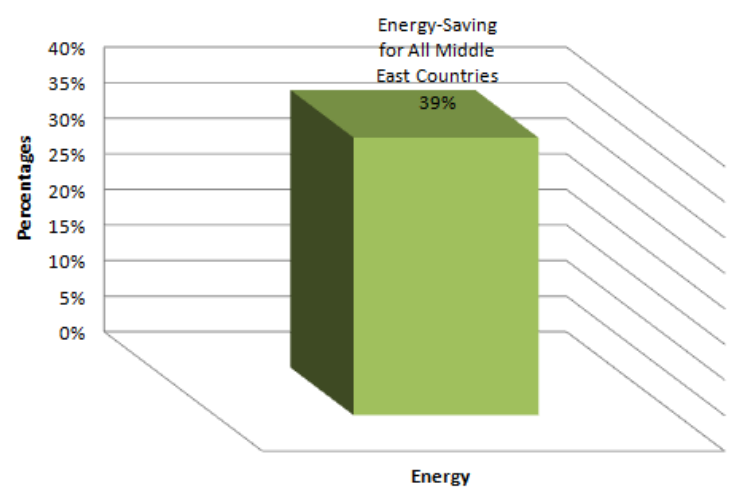

Figure 7. Savings in electricity consumption using thermal insulation and benefit from the orintation of the building

Applying the total saving from daylight, LEED lamps, and outer shell of the building on government and commercial buildings according to the Fig. 3 the saving will be illustrated in Fig. 8. Results in Fig. 8 show the percentage of the total saving of electricity in the green building compared to traditional buildings have reached $40 \%$.

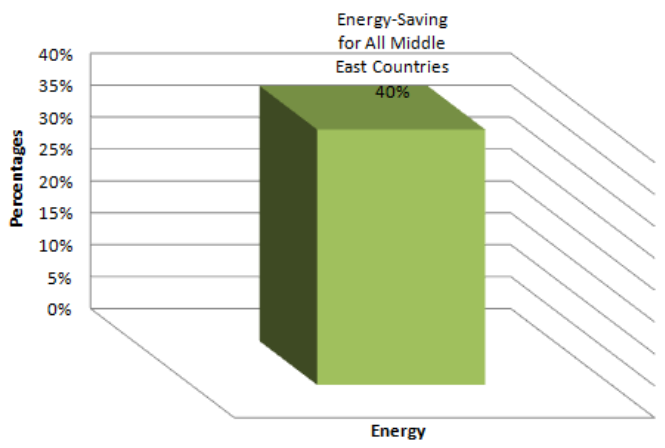

Figure 8. Savings in electricity consumption in green buildings compared to the traditional building building in the Middle East countries

\section{THE USE OF SOLAR PANELS}

This study has shown that green buildings are capable of providing saving of $40 \%$ of the building energy, which means that the building needs $60 \%$ of the energy compared to conventional buildings. Referencing to the geographical location and Longitude and latitude are resulting to the following: the number of hours of the brightness of daily sun in the Middle East is at least 5 to 5.9 hours per day, as shown in Fig. 9. This statistics of brightness hours is according to the winter days, where the number of sunshine hours less, which means that the annual average of the brightness of the sun is higher than 5 hours a day, and that has been showed in Fig. 9. The map in Fig. 9 shows solar isolation values for Europe, West Asia, and Africa. It could be noticed that the level of solar isolation in Saharan Africa is up to 7 times greater than that for Scotland in the UK, and at least 4-5 times greater than for the majority of locations in Northern and Central Europe. If it is for this reason that serious plans are being developed to power Europe from Sahara solar energy" [16], [17].

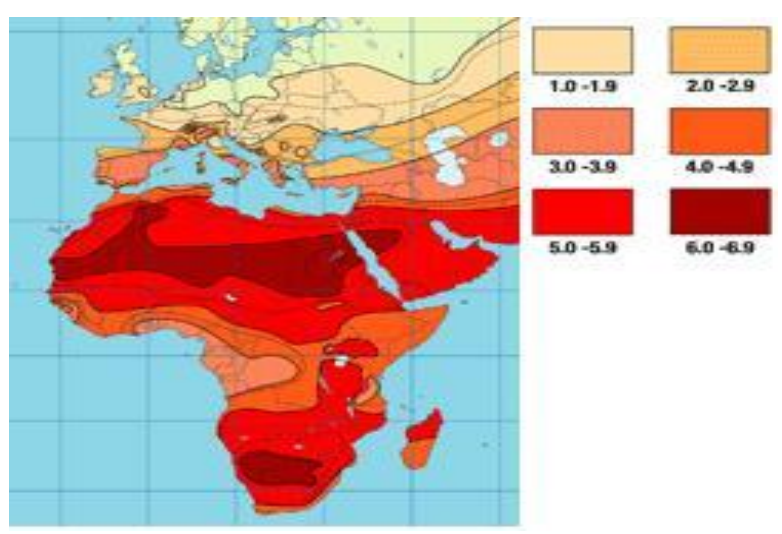

Figure 9. Number of hours that the sunshine on solar panels per day during the month less brighter year Ref. [18]

This study used a panel of type E20 / 327 SOLAR PANEL with an area of $1.63 \mathrm{~m}^{2}$ and the resulting energy $327 \mathrm{~W}$ [19]. Fig. 10 describes the solar irradiance in the Middle East countries is equal $2000 \mathrm{KWh} / \mathrm{m}^{2}$.

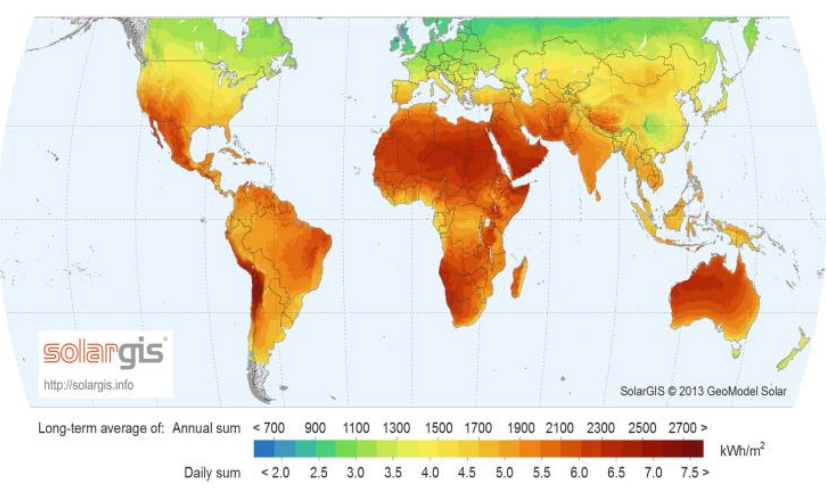

Figure 10. Average energy falling on a square meter of land for one year Ref. [18], [20]

Because of the great amount of energy that can be provided from the sun's rays from exploiting the roofs of these buildings. The study shows that this energy is sufficient to cover $60 \%$ of the energy needed by buildings, so these countries can get green buildings with consumption of $0 \%$ of Electricity distribution network. It follows that the renovated government and commercial buildings able to provide electric power alone and are not needed for the supply of electricity from Electricity network.

\section{GREEN BUILDINGS AND ENERGY CONSUMPTION}

This paper has proved that is possible the renovation of government and commercial buildings to green buildings and the ability of these buildings to rely on their self in energy saving and supplying, which provide the countries budget some money. Renovating environmental and commercial building into green building helps to get rid of the problem of power outages during the peak 
period. Results, which obtained from renovated buildings in this paper, proved that these buildings are friendly to the environment and protect the environment by reducing energy consumption, which in turn reduce the amount of electricity production, which relies heavily on polluting plants. Fig. 11 shows the proportion of energy consumption of government and commercial buildings of the total electricity consumption in these countries. The ratio of electricity consumption of public and commercial buildings of the some Middle East countries, ranging from $(16 \%$ to $50 \%)$. These variances of percentages which shown in Fig. 11 are due to the size of the country, population, and the percentage of growth and economic development.

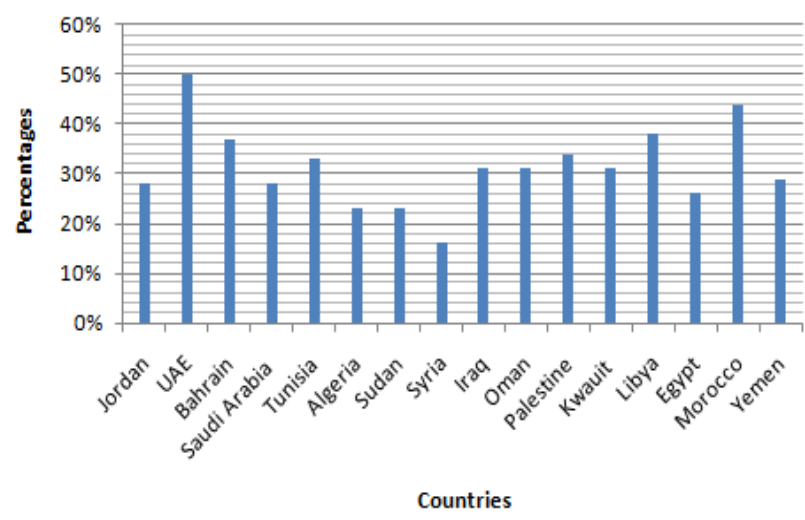

Figure 11. Proportion of electricity consumption of government and commercial buildings (Source statistical bulletin for 2013 of the Arab Union for Electricity) Ref. [21]

Fig. 12 shows the total consumption of electricity during one year by GW and the amount of consumption ranging from one country to another between (274503 to 3955) GW.

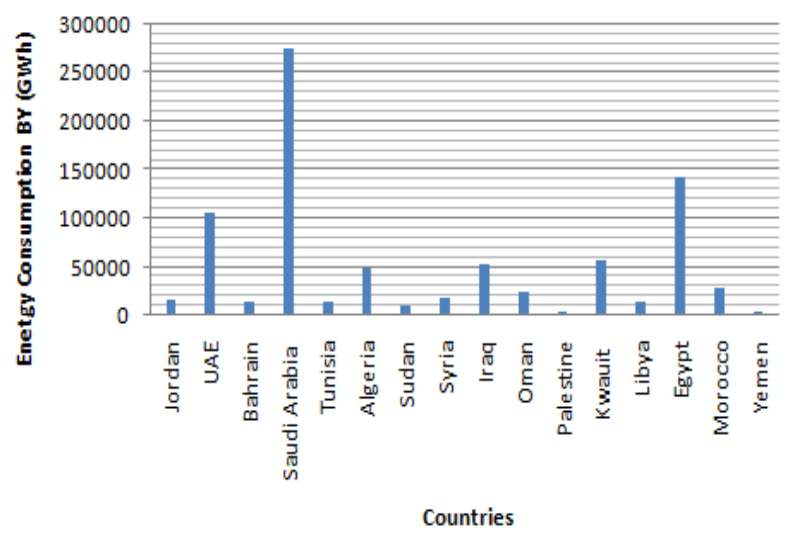

Figure 12. Total consumption of electricity (Source statistical bulletin for 2013 of the Arab Union for Electricity) Ref. [7]

Deducting these percentages of the electricity consumption of the government and commercial building from total consumption for each country as amount of the electricity saving in case these buildings are independent in electricity consumption as was shown in this study. It was saved $40 \%$ using green building and covered the rest using solar panels. Fig. 13 shows using the savings ratio of government and commercial buildings converted into green buildings and compared this ratio with the total energy produced for each country, and calculating the amount of electricity saving.

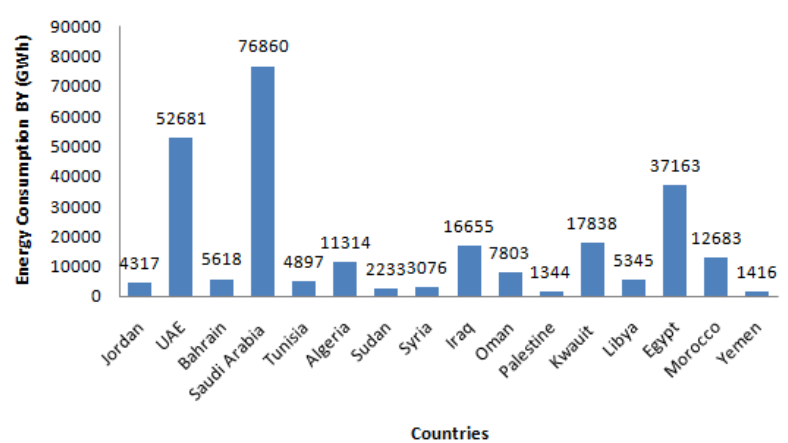

Figure 13. Amount of savings in electricity consumption in public and commercial buildings

The cost of the amount of electricity was calculated for each country separately using the pricing of electricity for each country (The price was taken from the Arab Union for electricity) and used with the saving amount of electricity in the Fig. 13. All accounts in US dollars. Fig. 14 illustrates saved cost of each country and were huge sums and ranging from (127 million dollars to 4.2273 billion dollars). In fact, these amounts saving save these countries very large cost, because the price of electricity collected as a result of consumption less than the production price; in other words, the price up to the citizen is less than the real price that must be paid, and that because of the contribution of these countries to support the pricing of electricity.

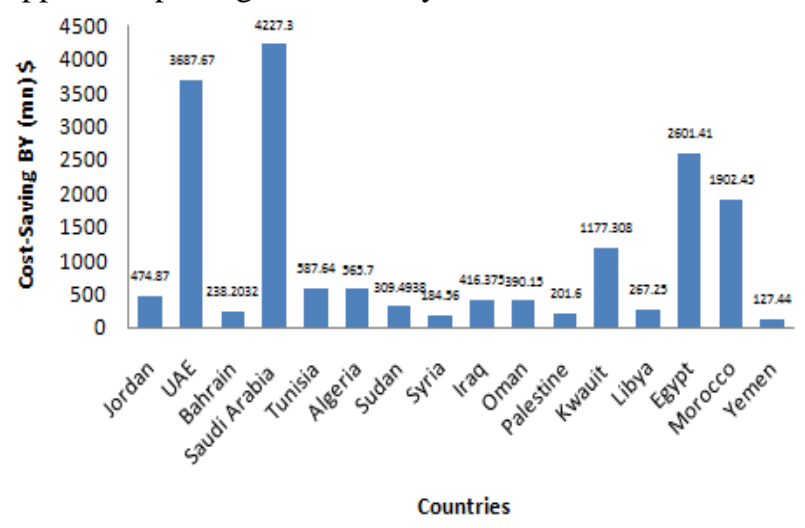

Figure 14. Amount of savings in electricity consumption in public and commercial buildings

In addition to the massive sums that have been saved by using green buildings in government and commercial buildings, will be reducing harmful emissions from power plants. As a result of lowering the proportion of electricity consumption as can be seen from Fig. 1, that is more than $88 \%$ of the energy produced from power plants is non-environmentally friendly.

In case solar panels are not used and only relay on the orientation of the buildings, the insulations, and the use of electrical light lamps according to LEED so savings will be just $40 \%$ as shown in Fig. 15, which is in US dollars. 


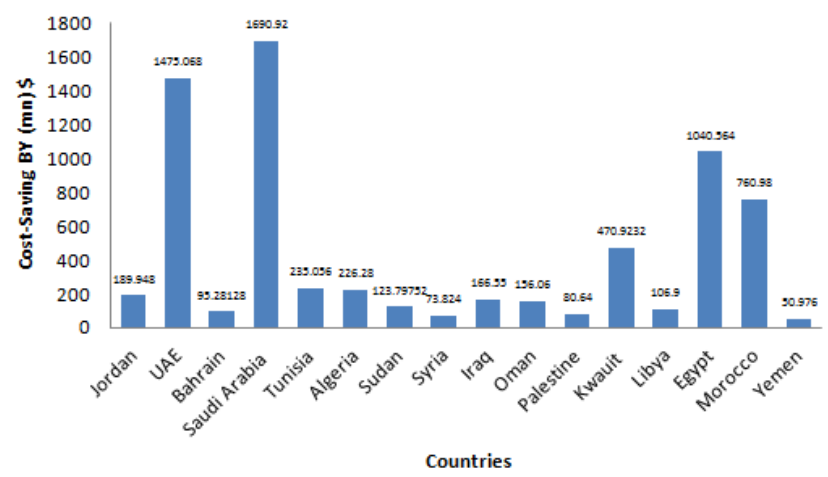

Figure 15. Amount of savings in electricity consumption in public and commercial buildings in the case of non-use of the solar panels

Fig. 16 shows the comparison of the savings by using green buildings with solar panels and the use of green buildings without solar panels.

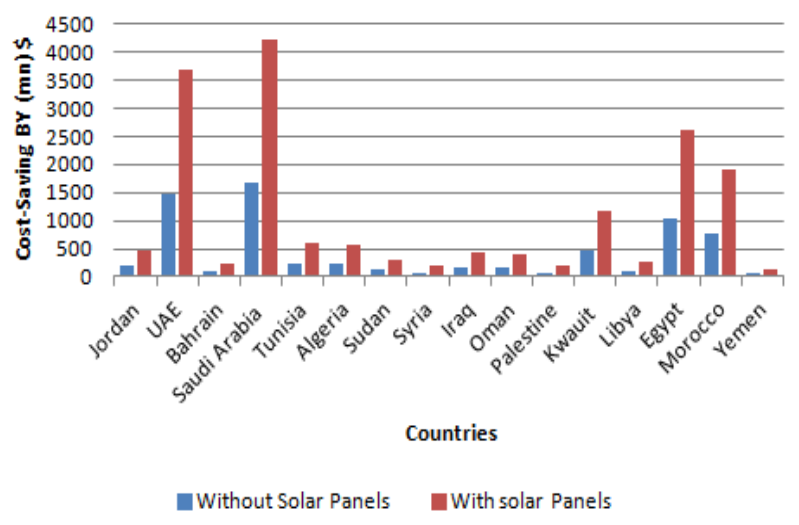

Figure 16. Comparison between the amount of savings in electricity consumption in public and commercial buildings in the case of the use of solar panels and not used

Even if not using the solar panels, these buildings still have a big impact on saving the energy and helping the budget of these countries.

\section{CONCLUSION}

This study has proved that green buildings have a significant impact solving the energy crisis and the growing demand in the future as well as saving large sums of money for the budget of Arab countries. The saving money from using green buildings could be invested in development projects to revitalize some Middle East economy, also saving the environment by cutting emissions of harmful gases by reducing the consumption of electricity; thereby reducing the production capacity of these stations. It has taken into account the following variables.

- The design of green buildings according to the geographical location of some countries of in the Middle East and to identify saving ratios.

- Taking advantage of the day light to reduce the use of electrical lighting.

- Choosing lamps according to LEED to reduce electricity consumption and heat emission.
- Taking advantage of the orientation of the building to reduce thermal transfer inside the buildings as well as the isolate areas that need to reduce heat transfer through them.

- Using solar panels to provide electricity to these buildings.

- Choosing the government and commercial buildings to renovate into green buildings.

- Taking advantage of savings ratios which have been obtained to minimize energy consumption.

- Illustrating the amounts of money that can derive from behind green buildings for the middle east countries.

For these reasons green buildings considered one of the most successful ways that experts looking for in Arabic countries for the rationalization of energy consumption. Green buildings are less expensive compared to other projects offered on the scene in the Arab world these days. Green buildings are not only money-saving but also maintaining the Middle East environment.

\section{REFERENCES}

[1] Indoor Air Quality Guide. Best Practices for Design Constriction, and Commissioning Developed by: America Society of Heating, Refrigerating and Air-Conditioning Engineers, The American Institute of Architects, Building Owners and Managers Association, International Sheet Metal and Air Conditioning Contractors' National Association, U.S. Environmental Protection Agency, U.S. Green Building Council 2009.

[2] Energy and Arab Cooperation 2014.

[3] M. S. Gul, S. Patidar, "Understanding the energy consumption and occupancy of amulti- urpose academic building," Energy and Buildings, vol. 87, pp. 155-165, 2014.

[4] S. P. Ramesh, M. E. Khan, "Energy efficiency in green buildingsIndian concept," International Journal of Emerging Technology and Advanced, vol. 3, no. 3, Feb 2013, pp. 329-336.

[5] A. C. Menezesa, B. A. Crippsa, R. A. Buswellb, J. Wrightb, and D. Bouchlaghemc, "Estimating the energy consumption and power demand of small power equipment in office buildings," Energy and Buildings, vol. 75, pp. 199-209, 2014.

[6] Arabic Union of Electricity 2014.

[7] Arabic Union of Electricity, Statistical Bulletin 2014.

[8] Arab Fund for Economic and Social Development 2014.

[9] M. Yahya, "Analysis and design green building as a case study according to the LEED in the Arabic region," Project, Fall 2015, Civil Engineering Department, Zawia University.

[10] S. K. Wang, Handbook of Air Conditioning and Refrigeration, 2001.

[11] Day lighting and window design "Lighting Guide LG10: 1999".

[12] New construction and major renovations LEED 2009.

[13] Philips catalogue 2014/15.

[14] M. A. F. A. Issawi, The Influence of He Outer Shell of the Building is Designed on the Acquisition of Thermal and Thermal Comfort for Users, 2003.

[15] S. Halliday, Sustainable Construction, 2008.

[16] B. Sead, Study about Insulation of Solar Panel, 2012.

[17] Reuk. [Online]. Available: http://www.reuk.co.uk/SolarInsolation.htm.

[18] [Online]. Available: https://en.wikipedia.org/wiki/Solar power in Africa.

[19] Sun power E-series residential solar panels E20-327.

[20] Solargis. [Online]. Available: http://solargis.com.

[21] Arab Union of Producers, Transporters and Distributors of electricity 2014. 


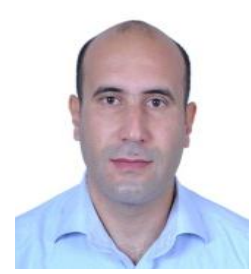

Mahmod Tayb M. Yahya. Holding Bachelors degree from University of Zawia at Civil engineering(spring 2005), Diploma at Structural engineering (concrete technology) from University of Tripoli in Libya(spring2009), and Masters degree in structural engineering form Wyane State University in USA

(December 2012).

$\mathrm{He}$ worked as lecture at College of Engineering, University of Zawia, and the coordinator of quality department, and currently works at Sabratha University as a lecture and projects coordinator. Has been working for several construction companies as a field and consultant engineer. 